\title{
Methane Production Controls in Thermokarst Lake Sediments
}

\author{
DR. ANDRE PELLERIN ${ }^{1}$, NOAM LOTEM ${ }^{1}$, EFRAT ELIANI \\ RUSSAK $^{1}$, NICHOLAS HASSON ${ }^{2}$, KATEY WALTER- \\ ANTHONY $^{2}$ AND ORIT SIVAN ${ }^{1}$
}

${ }^{1}$ Ben Gurion University of the Negev

${ }^{2}$ Unviersity of Alaska Fairbanks

Presenting Author: andrepellerin@gmail.com

Methane $\left(\mathrm{CH}_{4}\right)$ release to the atmosphere from thawing permafrost contributes increasingly to global $\mathrm{CH}_{4}$ emissions and exacerbates anthropogenic warming. In thawing permafrost, it is local redox conditions, the availability of electron acceptors, and the nature of the substrate under degradation that controls the microbial communities consuming organic matter and producing $\mathrm{CH}_{4}$. However, the short and long-term impacts of these different variables on the fate of organic matter in the Arctic and the global $\mathrm{CH}_{4}$ emissions are still unclear. The relationship between metabolic pathways responsible for organic matter degradation to $\mathrm{CH}_{4}$ and its relationship with the $\mathrm{CH}_{4}$ production rate were investigated in a young thermokarst lake in central Alaska.

Tracer incubations with labeled $2-{ }^{14} \mathrm{C}$ acetate and ${ }^{14} \mathrm{C} \mathrm{CO}_{2}$ indicates that the pathway of $\mathrm{CH}_{4}$ formation shifts from $\mathrm{CO}_{2}$ reduction-dominated in lithological layers of redeposited loess, to acetate disproportionation-dominated in layers of organic-rich peat. This shows that the pathway of $\mathrm{CH}_{4}$ formation is highly dependent on lithology. However, only small variations in $\mathrm{CH}_{4}$ production rates are observed between different lithological units. This indicates a relatively constant $\mathrm{CH}_{4}$ production rate despite different sedimentary depositional contexts. Therefore, regardless of the pathway involved, the net $\mathrm{CH}_{4}$ production appears disconnected from lithology.

$\delta^{13} \mathrm{C}$ and ${ }^{14} \mathrm{C}$ measurements of $\mathrm{CH}_{4}$ and organic matter show that $\sim 50 \%$ of $\mathrm{CH}_{4}$ dissolved in the porewater is produced below the first meter of the talik, indicating that deep $\mathrm{CH}_{4}$ production is significant to overall $\mathrm{CH}_{4}$ emissions. Integrating the $\mathrm{CH}_{4}$ production measurements down to the permafrost depth suggests that the predicted $\mathrm{CH}_{4}$ fluxes align with measurements of hotspot emissions and are only twofold higher than average $\mathrm{CH}_{4}$ emissions from the studied lake or other high- $\mathrm{CH}_{4}$-emitting thermokarst lakes.

These findings demonstrate that $\mathrm{CH}_{4}$ production rates and their integration over thaw depth gives a similar magnitude to $\mathrm{CH}_{4}$ emission estimates from water-saturated environments with deep thawing taliks. This indicates that in some situations, net $\mathrm{CH}_{4}$ emissions could be extrapolated from $\mathrm{CH}_{4}$ production measurements with only a few assumptions concerning lithology. The power and limitations of these assumptions will be discussed and expanded. 